BULLETIN (New Series) OF THE

AMERICAN MATHEMATICAL SOCIETY

Volume 42, Number 4, Pages 417-430

S 0273-0979(05)01072-4

Article electronically published on June 23, 2005

\title{
MATHEMATICS, MATHEMATICIANS, AND MATHEMATICS EDUCATION
}

\author{
HYMAN BASS
}

I am one of a growing number of research mathematicians who are substantially engaged with school mathematics education. Such outreach has a long and honorable tradition. In this lecture, I illustrate some of the ways that I think this can be helpful, and even essential.

Upon his retirement in 1990 as president of the ICMI 1 Jean Pierre Kahane spoke perceptively of the intimate connection between mathematics and mathematics education in the following terms:

- In no other living science is the part of presentation, of the transformation of disciplinary knowledge to knowledge as it is to be taught (transformation didactique) so important at a research level.

- In no other discipline, however, is the distance between the taught and the new so large.

- In no other science has teaching and learning such social importance.

- In no other science is there such an old tradition of scientists' commitment to educational questions.

It is this last point that frames my lecture.

Let me begin with some background observations. While university teaching is a substantial part of the academic mathematician's professional life, recent years have seen many research mathematicians involved in school mathematics education as well. There has been much attention to the so-called "math wars", an unfortunate term coined in the U.S. to describe the conflicts between mathematicians and educators over the content, goals, and pedagogy of the curriculum. Although these "wars" attracted a great deal of attention, the involvement of mathematicians has a much longer history in our profession. And most of that history is not primarily a history of conflict. In what follows, I will offer some snapshots from that history to provide a more robust picture of our tradition of concern for pre-college mathematics education. That tradition is both edifying and inspiring.

Received by the editors February 25, 2005.

2000 Mathematics Subject Classification. Primary 97B10, 97B20, 01A65, 01A70.

This paper is adapted from my plenary address at the International Congress on Mathematical Education in Copenhagen, 5 July 2004. Variants on this were presented also as my Retiring Presidential Address to the American Mathematical Society in Phoenix, Arizona, January 2004, and to the Center for Proficiency in the Teaching of Mathematics at the University of Michigan, December 2004. I am greatly indebted to my colleague Deborah Ball for generous discussions and critical feedback on its construction.

${ }^{1}$ International Commission on Mathematical Instruction.

(C)2005 American Mathematical Society Reverts to public domain 28 years from publication 
I choose specifically to focus on the involvement of research mathematicians, in part to dispel two common myths. First, it is a common belief among mathematicians that attention to education is a kind of pasturage for mathematicians in scientific decline. My examples include scholars of substantial stature in our profession and in highly productive stages of their mathematical careers. Second, many educators have questioned the relevance of contributions made by research mathematicians, whose experience and knowledge is so remote from the concerns and realities of school mathematics education. I will argue that the knowledge, practices, and habits of mind of research mathematicians are not only relevant to school mathematics education, but that this mathematical sensibility and perspective is essential for maintaining the mathematical balance and integrity of the educational process - in curriculum development, teacher education, assessment, etc.

Mathematics education is not mathematics. It is a domain of professional work that makes fundamental use of highly specialized kinds of mathematical knowledge, and in that sense it can, I suggest, be usefully viewed as a kind of applied mathematics. I will argue that, just as in other domains of "applied mathematics", the first task of the mathematician who wishes to contribute in this area is to understand sensitively the domain of application, the nature of its mathematical problems, and the forms of mathematical knowledge that are useful and usable in this domain.

The lecture has three parts:

I. A brief look at the work of two major historical figures.

II. Some observations on the contemporary scene.

III. A sample immersion into some of the work in which I have personally been engaged.

\section{A HISTORICAL VIEW (1870-1970):}

THE TRADITION OF INVOLVEMENT IN MATHEMATICS EDUCATION

For well over a century, a number of eminent research mathematicians have devoted substantial professional attention to mathematics education, even at the pre-college level. I have chosen two notable examples-Felix Klein and Hans Freudenthal - to illustrate the sorts of work that leading mathematicians have done in education. I chose them because of their stature in the field, the significance of what they did in mathematics education, and because their stories illuminate what mathematicians are able to contribute professionally 2 [3

\section{Felix Klein}

Felix Klein was born in Düsseldorf on 25 April 1849. (He was fond of pointing out that his birthday $\left(5^{2} / 2^{2} / 43^{2}\right)$ was formed of squares of prime numbers.) He was the first president of ICMI, an international organization founded in Berlin in 1908 by mathematicians in order to focus on educational issues of concern to mathematicians.

Klein's most famous mathematical legacy, inspired largely by conversations with Sophus Lie, is his Erlanger Programm, which re-conceptualizes geometries as the

\footnotetext{
${ }^{2}$ I have benefited here from the excellent account at ICME 10 by Geoffrey Howson (2004), of the careers of Klein and Freudenthal, and particularly of their relations to ICMI.

${ }^{3}$ Other mathematicians are similarly exemplary of this tradition-Henry Pollak or George Polya, for example-but I choose to focus here on Klein and Freudenthal for the interesting features that characterized their work in mathematics education.
} 
invariants of their symmetry groups. This was presented in a published paper on the occasion of his appointment, at age 23, to a Professorship at Erlangen University.

But this was not, as is commonly believed, the subject of his inaugural lecture (Antrittsrede) there. He chose instead, as the theme of his lecture, "the pedagogical principles and goals for my future academic activity." In other words, he gave an inaugural lecture on mathematics education (Rowe, 1985).

In his inaugural lecture Klein emphasized the unity of knowledge, in particular emphasizing close ties between science and the humanities. In mathematics, he advocated focused attention on applied, as well as pure, mathematics and on connections with the other sciences. While attending to rigor and logical skills, at the same time he strongly urged the cultivation of intuition and imagination. And, noteworthy for our theme here, he proclaimed the importance of giving serious attention to the mathematical preparation of school teachers.

Klein published over 30 articles and books dealing with educational matters. Notable among these is his book Elementary Mathematics from an Advanced Standpoint (Klein, 1924). This has been translated into several languages, and continues to be read with profit. His aim there is to provide for school teachers, and for their teachers as well, a robust mathematical perspective on the school mathematics curriculum. At the same time, he does not pretend that this fully prepares students for mathematics teaching, a task toward which he shows the greatest respect, sensitivity and even humility. For example, he writes (pp. 7-8):

What high regard one must have for the performance of elementary school teachers. Imagine what methodological training is necessary to indoctrinate over and over again a hundred thousand ... unprepared children with principles of arithmetic! Try it with your university training; you will not have great success!

Mathematicians who have not turned serious attention to mathematics education often fail to appreciate the cognitive and epistemological subtleties of elementary mathematics instruction. Here is a sample passage that evokes Klein's sensitivity to these matters.

Let us realize once and emphatically how extraordinarily difficult in principle is the step, which is taken in school, when negative numbers are introduced.... Here, for the first time, we meet the transition from concrete to formal mathematics. The complete mastery of this transition requires a high order of ability in abstraction.

What can we say about Klein's contributions to mathematics education? Klein embodied abundant qualities rarely seen in such harmonious combination in a single individual. He was a mathematician of astounding precocity and cultural breadth, with a lofty and unified view of the whole of mathematics of his day. He respected rigor, but favored intuition and imagination, and the meaning that mathematics takes from the sciences and the experiential world. He shed the light of disciplinary mathematics on school mathematics in ways that were remarkably sensitive to young learners and compassionate toward the challenges faced by their teachers. He was himself a gifted teacher to mathematicians and to future school teachers, whom he treated as professional partners and whose calling he honored. 


\section{Hans Freudenthal}

Freudenthal had remarkably broad mathematical and cultural interests. In mathematics he worked in topology, Lie groups, logic, and probability and statistics (for which he wrote a textbook). He also wrote a book on the popularization of mathematics, and he worked and published extensively in mathematics education. He was a gifted linguist, and even developed a proposed language for extraterrestrial communication. Howson (2004) reports that, during a heated argument with Dieudonné, Freudenthal protested, "Don't shout at me, for I can shout louder than you - and in more languages." Freudenthal was charming, mischievous, argumentative, autocratic, and an activist who accomplished many things.

Born and educated in Germany, Freudenthal took his first position with L. E. J. Brouwer in Amsterdam, just ahead of Hitler's rise to power. But the German invasion of Holland in 1940 forced Freudenthal, a Jew, into hiding for the duration of the war. During this time he wrote novels, one of which won a competition that he entered using the name of a non-Jewish friend!

Freudenthal viewed mathematics not primarily as a body of knowledge, but as a human activity, and he urged that mathematics education should do likewise. It should, he argued, be based in reality around phenomena that "beg to be organized" - a process he called "mathematization", a form of mathematical modeling of real problems or of organizing and synthesizing mathematical ideas. He opposed deductive approaches and favored instead development from the concrete to the general.

He was highly critical of most educational reform (New Math, or Mathématiques Modernes) and of the educational research of his day (both statistical and psychological). He believed in "mathematics for all", and favored small heterogeneous classes (no tracking/streaming).

Among Freudenthal's enduring cultural/institutional legacies in mathematics education are:

- Launching of the ICME' 4 with the inaugural congress held in Lyon in 1969. This year's meeting in Copenhagen was the tenth such congress.

- Founding of the international journal Educational Studies in Mathematics.

- Founding of what has come to be called the Freudenthal Institute at Utrecht University, which has had a pervasive influence on mathematics education in Holland and more broadly.

How can we characterize Freudenthal's contributions to mathematics education? While Klein was a mathematical ambassador to mathematics education, Freudenthal became a full-fledged, and even very prominent, citizen of the field. He became a knowledgeable and intellectually disciplined critic of the prevailing educational theories of his day. He brought strongly held beliefs and principles of his own, conveyed in his prolific writings. He was also a man of action. He enacted instructional experiments out of which he developed curricular and pedagogical ideas. And he built enduring institutions that continue to carry his legacy forward.

\section{Klein and Freudenthal: Setting a Standard}

Although their engagements in the domain were quite different, Felix Klein and Hans Freudenthal exemplify the long history of mathematicians' interest in pre-college mathematics education. Each brought his aesthetic dispositions about

\footnotetext{
${ }^{4}$ International congresses on mathematical education.
} 
mathematics to his view of the desirable nature of young learners' encounters with mathematics. Each considered in fine grain the special issues important to the mathematical integrity of the school curriculum. Still, the work that each contributed was distinctive. Klein examined and re-wrote a vision of the school level curriculum, offering a view of that curriculum that situated it in the larger mathematical landscape. He also sought to model both that mathematicians had important contributions to make and that humility in those contributions was essential. The creation of the International Commission on Mathematics Instruction (ICMI) set the foundation for institutionalizing connections between the mathematics and education community.

Freudenthal also worked explicitly to build new structures for interactions between mathematicians and mathematics educators; in particular the institution of the international congresses provided a regular context for exchange across national and disciplinary boundaries. But, unlike Klein, Freudenthal also engaged directly in improving students' mathematics learning opportunities. He developed substantial ideas about how young people should engage in mathematization and how this could support the development of mathematical skill and knowledge. His ideas provided the foundation for significant research and curriculum development work that continues to this day.

Klein and Freudenthal, each in his own way, exemplified how articulation of mathematical sensibility and perspective could influence the mathematics education of young people. And each helped to establish the legitimacy and possible nature of mathematicians' involvement in mathematics education. It is this tradition that I seek to highlight in this lecture.

II. THE CONTEMPORARY SCENE (1970-2004):

CURRENT INVOLVEMENT OF MATHEMATICIANS IN MATHEMATICS EDUCATION

In this brief survey of the contemporary scene, I shall concentrate mainly on the situation in the United States, with which I am most familiar. Variants of this scenario seem to have transpired in many other countries. First, I offer some background.

The "New Math" reforms in the U.S. (paralleled by the Mathèmatiques Modernes in Europe) can be seen to have emerged from the convergence of several trends:

1) Cold War competition and the growing public appreciation of the importance of mathematics, science and technology for national security;

2) the triumphs in mathematics of axiomatic methods, enshrined for example in the writings of Bourbaki;

3) the recognition that the school curriculum gave no hint of these spectacular scientific developments; and

4) the generally impoverished quality of school mathematics instruction.

Largely guided by mathematicians' views of the subject matter, new curricula prominently featuring axiomatic treatments of basic mathematical structures were developed for the schools, and teachers were quickly (and inadequately) schooled in this "New Mathematics", with the presumption that this knowledge equipped them to teach these novel ideas and perspectives to young children.

In my view, the focus within the New Math on mathematical structure remains an appropriate theme for school mathematics, and its loss has weakened the curriculum. New Math's critical failure was to naively implement this via abrupt 
axiomatic formalism rather than through a process of organic generalization from intuitive beginnings. This was fatal to its vision.

The shortcomings of the New Math precipitated in the U.S. a "Back to Basics" reactionary movement in the 1970 's, one that left mathematics education in a somewhat rudimentary state and whose outcomes came to again raise national alarm in the 1980's, signaled by the publication of A Nation at Risk (1983) from the U.S. Department of Education.

This time the response came not from mathematicians, but from educators, notably the National Council of Teachers of Mathematics, the professional organization of mathematics teachers. This led to the promulgation, for the first time in U.S. history, of new national standards for mathematics education (1989, 1991, 1995) 5 This was followed by the federally funded development of rather adventurous standards-based curricula, in whose construction research mathematicians had little voice. When these new curricula first entered classrooms and came to be known more concretely, some mathematicians (notably those with school age children) helped lead public protests whose effects we are still reconciling. They have expressed concerns over curriculum, standards, assessment, teacher preparation and professional development, and pedagogical practices.

In this environment of criticism and conflict, a number of eminent mathematicians have since rolled up their sleeves, taken their critiques to the ground level, and begun digging into important problems of school mathematics education. As mathematicians have by now gained a stronger voice in educational policy environments, they have also begun to gain better capacity to listen, and hear, as they work on the ground with practicing teachers and in more disciplined discourse with educational researchers.

Over time, the discourse has progressed from lengthy debate about standards, curriculum, and assessment to a more deliberative attention to teachers and teaching, which is seen to be the critical, and most challenging, domain for potential improvement in mathematics education. Mathematicians are particularly concerned with teachers' knowledge and understanding of mathematics. Recognition and support of the role and responsibility of mathematicians in this area was highlighted by the publication by the CBMS (an umbrella organization for the U.S. professional societies in mathematics) of The Mathematical Education of Teachers (2001), a report that has stimulated widespread and continuing efforts to strengthen the mathematical preparation of teachers.

Mathematics departments are giving more concentrated and higher quality attention to the mathematics courses they offer to pre-service teachers, and this has become a lively area of professional inquiry and growth. Individual mathematicians have engaged in various forms of professional effort, such as participation in professional development programs for practicing teachers, development of curricular materials for teacher education courses, and collaboration with education professionals in the design and implementation of instructional programs 6

\footnotetext{
${ }^{5}$ In fact, the NCTM Standards, having breached the sacred U.S. political tradition of local control of education, precipitated a "standards movement" in the U.S., one that extended beyond mathematics across other disciplines and that opened this arena to a somewhat politicized array of competing authors and critics of standards documents.

${ }^{6}$ Among the many U.S. research mathematicians who have been active in these ways, I mention, by way of illustration: Dick Askey (Wisconsin), Sybilla Beckmann (Georgia), Herb Clemens (Ohio
} 
III. LESSONS LEARNED BY 2004:

THE NEED FOR IMMERSION IN THE PROBLEMS OF SCHOOL MATHEMATICS EDUCATION

One observation, based on my brief narrative, is that the tradition exemplified by Felix Klein and Hans Freudenthal continues to thrive. The mathematicians to whom I alluded have devoted significant professional expertise and time to serious problems of school mathematics education.

But a second observation is that those contributions, the products of significant research mathematicians, are possible because they have developed a deep knowledge of the problems of pre-college mathematics. They have invested effort to learn about phenomena and environments, people and problems, very far from the everyday world of mathematical research.

That knowledge has, in turn, allowed them to see ways in which their mathematical knowledge and sensibilities offered resources for these problems, ways that have not always been those they would have first assumed or expected. A mathematical colleague, after his recent immersion in an eight-day intensive summer institute for mathematics teacher educators, testified, "I found myself thoroughly immersed in serious mathematical conversations about division of fractions, a fact that I still find rather amazing."

To illustrate the intensive mathematical engagement possible in problems of education, I turn finally to an example from my own experience. After a period of serving on education committees and in policy environments, I became more seriously engaged in mathematics education as an intellectual and professional endeavor. Over the past decade, I have been working with Deborah Ball and her research groups at the University of Michigan. A central question of our work is to better understand the mathematical knowledge and resources that elementary teachers need to do the work of teaching mathematics, work that must simultaneously respect the integrity of the mathematical ideas and also attend closely to the mathematical development of their students. What do teachers need to know, in what ways, and for what purposes? And how can they gain such knowledge? Unlike earlier approaches, ours has treated these as empirical questions, starting not with the school curriculum and the mathematical topics covered, but rather with the practice of teaching itself. We are doing a kind of "job analysis" to understand what kinds of mathematical problems teachers have to solve in the course of their daily work, and what kinds of mathematical resources they deploy in solving those problems (Ball and Bass, 2003).

This has taken me into a closer study of the challenges and possibilities of elementary mathematics instruction than I first imagined. One point I want to emphasize is that my perspective and sensibility, as a research mathematician, gave me a lens in this kind of observation of instructional practice that made visible important things that would be missed by others with different training and expertise, just as their lenses have expanded my own vision.

This work has provided an emerging theory of what we have named mathematical knowledge for teaching (MKT), together with the development of instruments to measure such knowledge and its growth (Ball, Bass, and Hill, 2003; Hill, Schilling,

State), Roger Howe (Yale), Jim Lewis (Nebraska), Bill McCallum (Arizona), Jim Milgram (Stanford), Tom Parker (Michigan State), Robin Pemantle (Pennsylvania), Judy Roitman (Kansas), Paul Sally (Chicago), and Hung-Hsi Wu (Berkeley). 
and Ball, 2003). I shall say more about this below. But first, in order to give you a more vivid sense of this kind of work, I invite you now to examine an episode from a real elementary mathematics lesson. What does it mean (and feel like) to look analytically at real teaching practice with a mathematical eye?7

\section{Using a Mathematical Perspective to Study Teaching 8}

We now visit a class of 19 third graders ( 8 year-olds) 9 The class is culturally and linguistically diverse (many speaking English as a second language, and some only recently arrived in the U.S.). This is not meant to illustrate exemplary instruction or a particular pedagogical style, but rather to provide an example that makes vivid and visible some of the complex mathematical work of teaching. The philosophical orientation of the instruction was: (1) to work on substantial mathematics and treat the mathematics with integrity; (2) to take students' thinking seriously and make it an integral part of the instruction; and (3) to treat the construction of mathematical knowledge as the work of an intellectual collective, with mathematical justification and critical evaluation of solutions and claims being a central demand of the student work.

The children were working on even and odd numbers. They came to third grade "knowing" which (small numbers) were even and which were odd, but without any formal definition of these notions. In this class, the topic was introduced through investigation of problems such as this one:
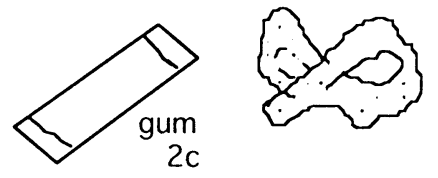

big pretzel

$7 c$

Mick has 30 cents in his pocket and he wants to spend it all (on gum and pretzels) and not have any change left in his pocket. What can he buy for 30 cents? What are his choices?

The solution to this problem pushed the children into encounters with notions of even and odd numbers, and eventually to make conjectures about their arithmetic properties (e.g., even + odd $=$ odd, odd + odd $=$ even, etc.).

On one particular day, the students were preparing to work on these conjectures, seeking to determine whether they were true for all numbers. Near the beginning of the lesson, one of the boys, Sean, reflecting on a discussion they had had the previous day, raises his hand and says,

I was just thinking about six, that it's a. . I'm just thinking it can be an odd number, too, 'cause there could be two, four, six, and two, three twos, that'd make six.... And two threes, that it could be an odd and an even number. Both! Three things to make it, and there could be two things to make it.

\footnotetext{
${ }^{7}$ In my lecture, I showed the seven-minute video of the lesson; here, instead, we shall have to make do with a narrative based on its transcript.

${ }^{8}$ This work has been supported by grants from the National Science Foundation (REC \#0126237) and the Spencer Foundation (MG \#199800202).

${ }^{9}$ These data were collected under a 1989 National Science Foundation grant to Ball and Magdalene Lampert, then at Michigan State University.
} 
Hearing this, it is difficult to resist forming quick opinions about Sean's thinking or asserting what the teacher should do. ("Why doesn't the teacher just set the students straight?") But, before even considering such judgments, we should address the more difficult question, "What is significant mathematically about what is actually going on in this episode? What can we see? What might be helpful for a teacher to see, and be sensitive to, mathematically?"

The teacher does not immediately challenge or correct Sean. She re-voices and tries to publicly clarify what he is saying, at which point she invites comments from the class. His classmates quickly express disagreement. Everyone already knew from second grade that six is even. We watch as this mathematical debate unfolds, attending to how the children are processing mathematical ideas and claims, and to the mathematical moves of the teacher to shepherd this discussion.

Cassandra, the first to object, points to the number line above the blackboard, saying,

Six can't be an odd number because this is (she points to the number line, starting with zero) even, odd, even, odd, even, odd, even, .... Because zero's not an odd number.

Sean persists,

.... because there can be three of something to make six, and three of something is like odd....

Then Kevin protests, "That doesn't necessarily mean that six is odd." Several students chime in, "Yeah." When the teacher asks Kevin, "Why not?" he responds,

Just because two odd numbers add up to an even number doesn't mean it has to be odd.

At this point the teacher, thinking that Sean may be just confused about the meaning of "even", makes an important mathematical move, asking,

Sean. What's our working definition of an even number? Do you remember from the other day the working definition we're using?

When Sean can't remember, she asks several other students, until Jillian offers,

It is, um, if you have a number that you can split up evenly without having to make (long pause) to split one in half, then, um, it's an even number.

When the teacher then asks Sean if he can do that with six, he agrees, so she says,

So then it would fit our working definition; then it would be even, okay?

To which Sean comfortably responds,

And it could be odd. Three twos could make it.

Sean, contrary to the tacit understanding of the class, seems to allow that a number can be both even and odd. The teacher then realizes that to mediate this discussion requires a definition of odd numbers as well as one for evens, something she had not before thought necessary. After some discussion, the class agreed that odd numbers were those you could not split up fairly into two groups. But Sean is tenacious, saying that you could split six fairly (two threes) and not fairly (three twos).

To clarify Sean's thinking, the teacher pursues a new line of questioning and asks Sean if he thinks all numbers are odd then. When he says no, she asks him which numbers are not odd. He says that 2, 4 and 8 are not odd, but that 6 can 
be odd or even. Several students shout, "No!" And Tembe challenges him: "Show us." Sean only repeats, "There are three twos; one, two; three, four; and five, six." Unconvinced, Cassandra and Tembe insist, "Prove it to us that it can be odd." The teacher then invites Sean to prove it to the class and asks everyone to pay close attention. Sean goes to the board, where there is a drawing of six circles, which he then proceeds to separate into groups of two,

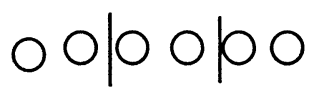

saying, "There's two, two, and two. And that would make six." To which Cassandra rejoins, "I know, which is even." And Tembe backs her up.

Then Mei raises her hand to say, "I think I know what he is saying." The teacher asks Sean to remain at the board while Mei explains,

.... I think what he's saying is that you have three groups of two.

And three is a odd number so six can be an odd number and an even number.

Notice here that the question is no longer whether Sean is right or wrong, but whether Mei has correctly interpreted Sean's idea and argument. The teacher first gets Sean's confirmation of this, and then she asks if others agree with Sean. After having clearly articulated Sean's argument, Mei herself then says,

I disagree with that because it's not according to like... here, can I show it on the board?

At the board, facing Sean, Mei continues,

It's not according to like... how many groups it is. Let's say that I have (long pause while she thinks)... Let's see. If you call six an odd number, why don't (pause)... let's see (pause)... let's see - ten. One, two,... (draws circles on board) and here are ten circles. And then you would split them; let's say I wanted to split, split them, split them by twos.... One, two, three, four, five,... (she draws the dividing lines and counts the groups of two).

\section{o olo olo olo olo o}

Then why do you not call ten a, like... an odd number and an even number, or why don't you call other numbers an odd number and an even number?

What is Mei doing here? First she has understood and given a clear public expression of Sean's idea, one with which she in fact disagrees, and she has pinpointed the fault in Sean's argument. ("It's not according to how many groups.") But she goes well beyond the mere statement of that critique. She cleverly constructs an argument that she is persuaded will make Sean, in his own terms, see the error of his ways. She generalizes the principle of Sean's reasoning - that six is made of an odd number of groups of two - and so sees that this same criterion would usher in an unlimited supply of new odd-and-even numbers, to her a menacingly uncertain predicament that she fully expected Sean to back away from. Her reflective 
pauses were needed to search mentally, while the class waited quietly, for the next example - 10 - of an odd number of groups of two.

To Mei's surprise, and then dismay, Sean responds,

I disagree with myself.... I didn't think of it that way. Thank you

for bringing it up; so, I say it's... ten can be an odd and an even.

In this ironic exchange, Mei, intending to shock Sean with the extravagant implications of his reasoning, in fact succeeds instead in giving Sean an expanded understanding and appreciation of his own idea, which he embraces with thanks. Mei's argument is mathematically astute, well expressed, and well understood by Sean (and the class, as we later see). Mei and Sean differ in the significance that they each attach to it. Exasperated, Mei then proclaims,

Yeah, but what about other numbers?! Like, if you keep on going on like that and you say that other numbers are odd and even, maybe we'll end it up with all numbers are odd and even. Then it won't make sense that all numbers should be odd and even, because if all numbers were odd and even, we wouldn't even be having this discussion!

Noteworthy here is Mei's mathematical sensibility about definitions, that they fail in their purpose if they lose the capacity to make significant distinctions, to give concepts appropriately sharp boundaries.

In these few moments of mathematics instruction, what can we observe about the mathematics going on? First of all, what mathematics are the children doing and learning? On one level they are exploring aspects of even and odd numbers. But, perhaps more significantly, they are engaged in substantial mathematical discourse and reasoning. The children are making mathematical claims and counterclaims, and critically examining each other's ideas. There is an imperative for justification of claims that the children take to heart and to which they hold each other accountable. Such mathematical practices, much as we rhetorically advocate them, are not learned if they are not taught and practiced. That entails an instructional investment that we can see manifested in this episode.

To reconcile mathematical disagreement, the teacher recognizes the need for definitions of the mathematical terms in play. She asks the class to make explicit the "working definition". In fact three definitions of even (and odd) numbers are implicitly in use: fair share (a number is even if it can be split into two equal groups), pair (a number is even if it is composed of groups of two), and alternating (the even and odd numbers alternate on the number line, with zero being even). These are not all explicitly stated or shown to be mathematically equivalent, but they are tacitly assumed to be so. Some students (not Sean) assume the "even" implies "not odd". Noticing these different definitions in the children's reasoning, realizing the need to reconcile them, and considering what is entailed in establishing their equivalence are all crucial for teachers to know. It is also important for teachers to know what are mathematically appropriate and usable definitions of even and odd numbers for third graders. Mathematical reasoning is not feasible without some careful attention to commonly understood mathematical definitions. For example, proving the conjectures (e.g., odd + odd $=$ even) depends on the use of definitions.

Though Sean misuses the mathematical terms "even" and "odd", he nonetheless has a clear mathematical idea about six: he notices that it has "an odd way of being even." But, lacking vocabulary to name this feature, he misguidedly appropriates 
the name "odd-and-even" for it. Sean is thinking only about six. But Mei recognizes that Sean's argument about six is generalizable and opens the door to far-reaching possibilities that she assumes would cause Sean to retreat from his claim: No such luck.

A side comment to indicate some of the mathematics hovering around this lesson: Mathematical ideas typically admit multiple generalizations. Mei generalized Sean's idea to numbers that are an odd number of groups of two (twice an odd number). Another plausible candidate would be numbers that are an odd number of groups of any size, in other words, numbers with an odd factor $(>1)$. In other words, numbers which are not powers of two. Would Sean have equally well embraced this generalization? Had the teacher, or a student, wanted to probe this possibility, an interesting mathematical question is then what number to ask Sean about. In this case, the first test case would be, not ten, but twelve $(=2 \times 6=3 \times 4)$.

What are these "Sean numbers" (as the teacher came later to call them) introduced by Mei? Odd multiples of two. Is this a topic worthy of instructional time? Even and odd are about mod 2 arithmetic. Sean has cracked the door open on mod 4 arithmetic, identifying numbers congruent to $2 \bmod 4$. These turn out also to be exactly those natural numbers that are not a difference of two squares. So, the idea surfaced by Sean's natural curiosity about numbers in fact has some interesting mathematical significance that he could not have anticipated, but that might figure in the teacher's evaluation of how much instructional play to give it. Indeed, once Mei had essentially defined these Sean numbers, the students eventually began an exploration of their properties - finding patterns (every fourth number, starting with two, is one); making and proving conjectures (a sum of Sean numbers is not one); etc.

But, more importantly, what the children are learning is, beyond the properties of Sean numbers, the skills of mathematical exploration and reasoning, generalization, use of mathematical definitions, etc. For people who wonder in frustration over our students' failure to gain proficiency with or appreciation of mathematical reasoning, you might consider that this provides one image of what it might look like for young children to begin to develop such skills.

\section{Mathematical Knowledge for Teaching (MKT)}

Let me turn now briefly to the area in which I have focused, working closely with Deborah Ball and others in our University of Michigan research group. I begin with a bit of context.

Many teachers have not had good mathematical preparation and lack adequate mathematical knowledge for teaching. This is an enormous problem in the U.S., and from what I have learned from reading and from my international colleagues, teachers' mathematical preparation is a problem in many other countries as well. I focus here on those who teach at the primary level, but strong evidence suggests that there are similar problems as well at the secondary level.

This is an important problem - for practice, policy, and theory - and many solutions are offered. Most solutions consist of increasing the requirements for teachers. But what these requirements should consist of is too often taken for granted and left unspecified.

Our method is to turn this problem "upside down" and begin, not with the school curriculum and the related disciplinary mathematics, but rather with teaching practice itself. The basic question is thus transformed into, "What is the mathematical 
work of teaching?" To answer this question, we, naturally enough, study actual teaching, including the work that teachers do inside and outside of classrooms to teach mathematics. Our examination above of an episode of teaching gives one glimpse of what is entailed in such study of practice. From such observations we analyze the mathematical demands of that work, demands that often go unnoticed and that we are learning are quite substantial. This in turn informs our evolving, practice-based answer to the question, "What is mathematical knowledge for teaching (MKT)?" Understanding this is important to improving teachers' mathematical preparation.

We use the term "mathematical knowledge for teaching" to represent the mathematical knowledge, skills, habits of mind, and sensibilities that are entailed by the actual work of teaching. And by the "work of teaching" we mean the daily tasks in which teachers engage, and the responsibilities they have, to teach mathematics, both inside and outside the classroom, for example: planning lessons, designing and modifying tasks, communicating with parents about their children's work and progress, introducing concepts, writing and assessing tests, etc. These comprise the specialized tasks in which teachers need to know and use mathematics in a variety of ways.

An important strand of our work, led by Heather Hill and Deborah Ball, is the development of measures of mathematical knowledge for teaching (Hill, Schilling, and Ball, 2004; Hill, Rowan, and Ball, in press). In the course of this we have found it natural and useful to distinguish four different categories of MKT: (1) Common mathematical knowledge (expected to be known by any well educated adult); (2) Specialized mathematical knowledge (strictly mathematical knowledge that is particular to the work of teaching, yet not required, or known, in other mathematically intensive professions (including mathematical research)); (3) Knowledge of mathematics and students; and (4) Knowledge of mathematics and teaching. For example, in connection with multi-digit multiplication, MKT includes things like: (1) knowing how to calculate; (2) knowing how to analyze both correct (non-standard) and incorrect solutions; (3) identifying the student thinking that might have produced an incorrect answer, or knowing likely student errors; and (4) knowing what kinds of materials or representations would be best suited to explaining why and how some standard algorithm works.

A noteworthy finding is the identification and characterization of specialized mathematical knowledge for teaching (category (2)). It is to be expected that teachers need some knowledge - about students (3) and about pedagogy (4) - that other professionals would not need or be expected to know. But specialized knowledge of mathematics is strictly mathematical knowledge (not about students or about pedagogy) that proficient teachers need and use, yet is not known by many other mathematically trained professionals, for example, research mathematicians. Thus, contrary to popular belief, the purely mathematical part of MKT is not a diminutive subset of what mathematicians know. It is something distinct, and, without dedicated attention, it is not something likely to be part of the instruction in content courses for teachers situated in mathematics departments.

To summarize some of what we are learning:

1. A practice-based approach to asking about mathematical knowledge for teaching reveals that there is much mathematics deep inside the school curriculum as well as beyond it. 
2. Knowledge needed for teaching is different from that needed for other occupations or professions where mathematics is used.

3. Knowledge needed for teaching must be usable for the specialized mathematical problem solving and reasoning that teachers have to do.

\section{CONCLUSION}

Let me conclude here by summing up my argument about productive interactions among mathematics, mathematicians, and mathematics education.

- The mathematics profession has a long and honorable tradition of involvement in mathematics education.

- Eminent mathematicians from around the world, and throughout history, have exemplified this tradition.

- Important contemporary mathematicians are continuing, and expanding, this tradition.

- This work can be productively pursued in the spirit of "applied mathematics" by first deeply understanding the domain of application.

- As practitioners of the discipline, research mathematicians can bring valuable mathematical knowledge, perspectives, and resources to the work of mathematics education.

- This is a tradition worthy of continued development and support.

\section{REFERENCES}

Ball, D. L. and Bass, H. (2003). Toward a practice-based theory of mathematical knowledge for teaching. In B. Davis and E. Simmt (Eds.), Proceedings of the 2002 Annual Meeting of the Canadian Mathematics Education Study Group (pp. 3-14). Edmonton, AB: CMESG/GCEDM.

Hill, H., Rowan, B. and Ball, D. (in press). Effects of teachers' mathematical knowledge for teaching on student achievement. American Educational Research Journal.

Hill, H. C., Schilling, S. and Ball, D. (2004). Developing measures of teachers' mathematical knowledge for teaching. Elementary School Journal.

Klein, Felix (1924). Elementary Mathematics from an Advanced Standpoint. Arithmetic-AlgebraAnalysis. Translated from the 3rd German edition by E. R. Hedrick and C. A. Noble, Dover Publications, New York (1953), ix+274 pp. MR0055397 (14,1068e)

Rowe, David E. A forgotten chapter in the history of Felix Klein's Erlanger Programm. Historia Mathematica, Vol. 10 (1983), no. 4, 448-454. MR0726337 (86b:01022)

Rowe, D., Felix Klein's "Erlanger Antrittsrede", a Transcription with English Translation and Commentary, Historia Mathematica, 12 (1985), 278-291. MR0795134 (86k:01030)

Howson, A. G. (2004). Klein and Freudenthal: Two rocks on which to build. Regular Lecture, ICME 10, Copenhagen, July 2004.

National Commission of Excellence in Education (1983). A Nation at Risk: The Imperative for Educational Reform. Washington, DC: U.S. Government Printing Office.

National Council of Teachers of Mathematics. Curriculum and Evaluation Standards for School Mathematics (1989). Professional Standards for Teaching Mathematics (1991). Assessment Standards for School Mathematics (1995). Reston, Virginia.

Conference Board of the Mathematical Sciences (2001). The Mathematical Education of Teachers. Mathematical Association of America, in cooperation with the American Mathematical Society, Providence, Rhode Island.

2413 School of Education, University of Michigan, 610 E. University, Ann Arbor, MiCHIGAN 48109-1259 